\title{
The challenges of evaluating environmental interventions to increase population levels of physical activity: the case of the UK National Cycle Network
}

\author{
D A Lawlor, A R Ness, A M Cope, A Davis, P Insall, C Riddoch
}

J Epidemiol Community Health 2003;57:96-101

\section{PHYSICAL ACTIVITY AND PUBLIC HEALTH}

Regular, physical activity is associated with increased life expectancy and reduced risk of coronary heart disease, stroke, diabetes, hypertension, obesity, and osteoporosis. ${ }^{1-3}$ It has been suggested that promoting physical activity is "public health's best buy". ${ }^{4}$ However, most people are not regularly active and the challenge remains as to how "more people" can be encouraged to be "more active, more often". ${ }^{5}$ To date, most public health interventions to increase levels of physical activity, such as media campaigns or primary care based "exercise on prescription schemes", have focused on individual behaviour change. At worst these have no overall effect and at best they result in increased levels of activity in only a small proportion of the population and that are seldom maintained long term. ${ }^{6-9}$ This may not be surprising as these interventions are in effect trying to persuade individuals to participate in activities in environments that are (or are perceived to be) hostile to the very activities they promote. ${ }^{10}$ Modification of social, economic, and environmental factors may yield greater population health dividends than individual lifestyle approaches. ${ }^{12}$ Indeed such interventions may be necessary before individual lifestyle approaches can be effective. ${ }^{10}$

In this paper we will discuss the potential role of environmental strategies to increase population levels of cycling and walking; describe one such UK intervention-the UK National Cycle Network; discuss the challenges of evaluating this project and suggest appropriate ways of assessing its effect on population levels of physical activity.

\section{THE POTENTIAL PUBLIC HEALTH IMPORTANCE OF CYCLING AND WALKING}

Regular participation in moderately intense activity, such as brisk walking and cycling, is associated with health benefits. ${ }^{13}$ Activities that can become part of every day life, such as walking or cycling to work or school, are more likely to be sustained than activities that require attendance at specific venues. ${ }^{13}$ Therefore, walking and cycling offer an effective means of increasing population levels of physical activity and improving health.

Cycle ownership in the UK has increased from $14 \%$ in $1975 / 76$ to $32 \%$ in $1995 / 97 .{ }^{14}$ This suggests that many people wish to cycle but something prevents the transition from intention to actual participation. In the past many more journeys were made by bicycle ( fig 1). Furthermore, the number of short journeys (of less than half a mile) undertaken by car has increased from under $4 \%$ of all car journeys in the early 1980s to about $25 \%$ by the late 1990 s. $^{15}$ These short trips often take

*Sustrans is a registered charity (number 326550 ) dedicated to practical measures for the promotion of non-motorised transport. Sustrans stands for Sustainable Transport. as long, or longer, by car than they would on foot or by cycle, ${ }^{15}$ suggesting that people do not necessarily choose the car because they have further to travel now than in the past or because the car is faster.

\section{ENVIRONMENTAL BARRIERS TO INCREASING CYCLING AND WALKING}

Various lines of evidence suggest that the environment has an important impact on levels of regular activity. In ecological studies the number of safe and convenient walkways is positively associated with higher levels of regular walking. ${ }^{16}$ In one study, after adjustment for potential confounding factors, residents who lived in coastal areas were $23 \%$ less likely to be sedentary and $27 \%$ more likely to participate in levels of activity that were adequate for health improvement, than residents in similar, but inland, areas. ${ }^{17}$ In a US study residents in areas of Los Angeles that were laid out in a "traditional grid system" were up to $25 \%$ more likely to regularly walk to work compared with residents in socioeconomically similar areas that were laid out specifically for cars. ${ }^{18}$ A survey among adults from six European countries suggested that both moderate and vigorous levels of activity were influenced by perceived environmental factors that encouraged activity. ${ }^{19}$ In an in depth interview study low income mothers of young children expressed the view that walking through the depressed and neglected areas in which they lived would be more likely to have a negative rather than positive impact on their own health and that of their children. ${ }^{10}$

\section{THE UK NATIONAL CYCLE NETWORK}

Development of the UK National Cycle Network has been initiated and coordinated by the charity Sustrans (Sustrans

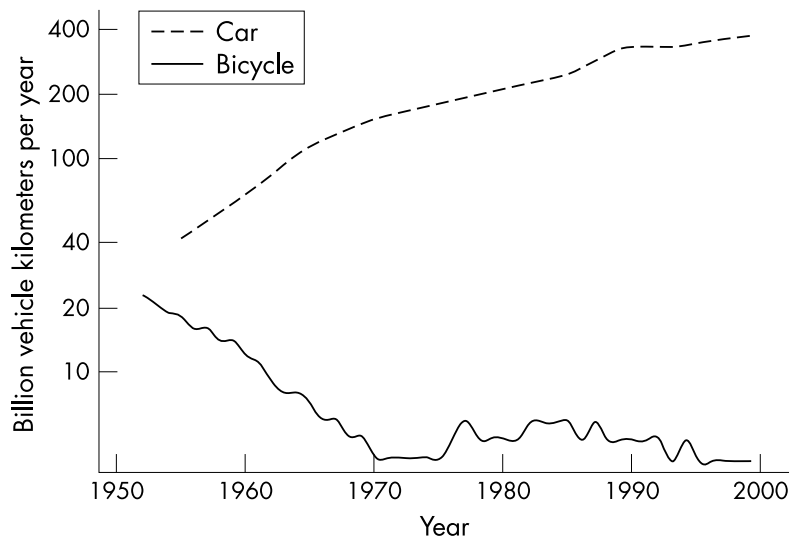

Figure 1 Secular trends in cycling and car use on public roads in Great Britain, 1952-1999, mean billion vehicle kilometres per year, plotted on a log scale to emphasis rate of change over time. Source: Department of Environment and Transport and the Regions. ${ }^{24}$ 


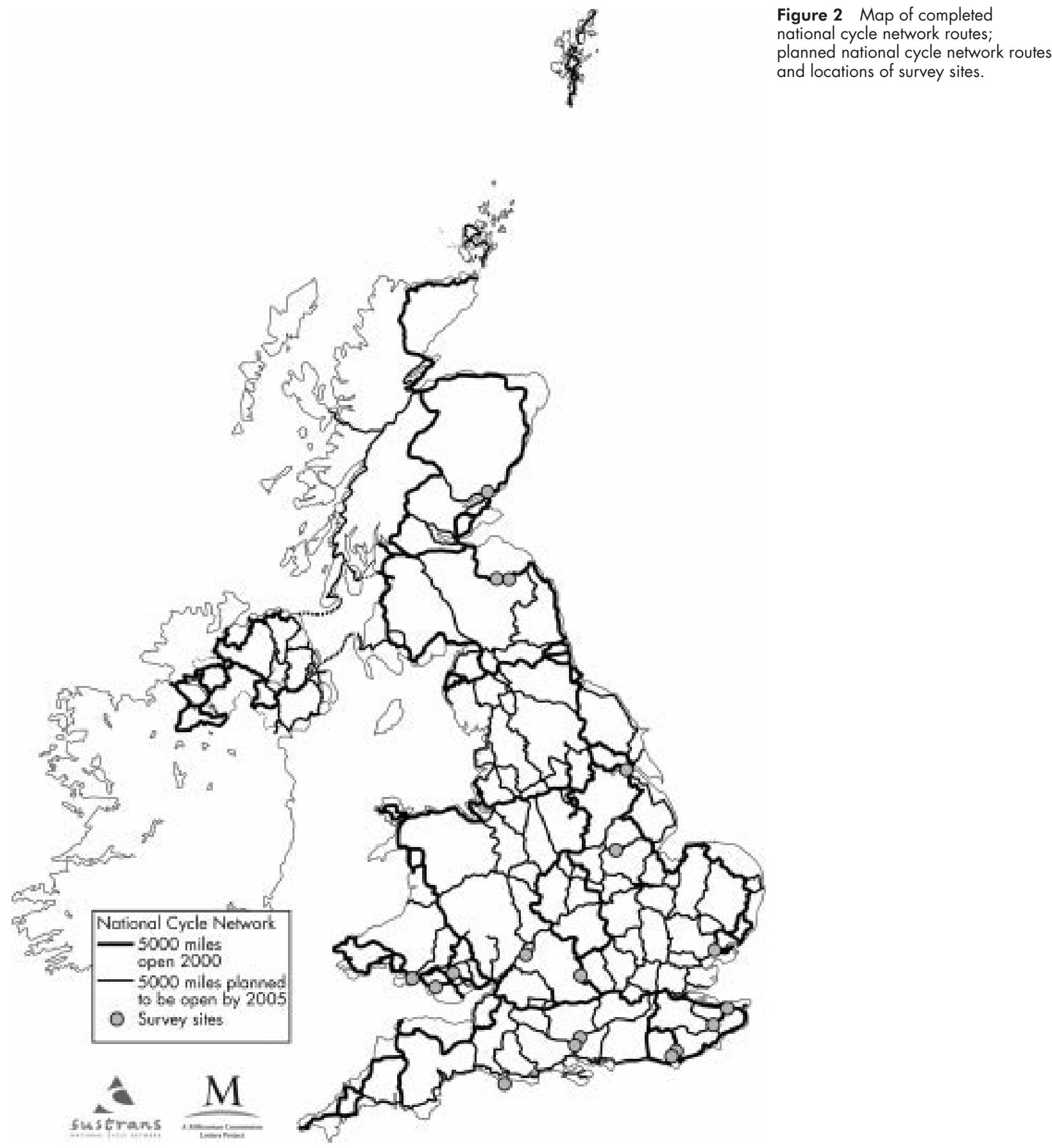

stands for sustainable transport). Sustrans was established in 1978 as a community group in Bristol, south west England, to design and create traffic free paths for cyclists and pedestrians; over the next few years it expanded to work on a national scale. Sustrans objective was to promote non-motorised forms of transport as more environmentally responsible alternatives to the private car. This objective was later widened to include other potential benefits, including the promotion of healthy physical activity.

In 1995 Sustrans proposed a structured programme to use new and existing traffic free paths to link quiet and traffic calmed roads into a UK national cycle network (fig 2). The purpose was to tackle the overall objectives of Sustrans and also to increase cycling levels in the UK to levels similar to other European countries with more cycle friendly transport systems $(18 \%$ of routine journeys in Denmark are made by bicycle, comparable figures for Switzerland, Germany, and Sweden are $15 \%, 11 \%$, and $10 \%$ but for the UK this figure is only $2 \%^{20}$ ). The proposal requested 500 partner bodies to collaborate on the development of an $8000 \mathrm{~km}$ first phase network, for completion by June 2000. This first phase was successfully completed, and work is now in progress to extend the Network to $16000 \mathrm{~km}$ by summer 2005 .

The partners include local (government) authorities, national groups active in environmental, transport, recreation, health and social welfare, local organisations and community groups active in these fields, and major landowners such as British Waterways, the National Trust, and the Forest Enterprise. The project also has the support of thousands of individuals, as planning, construction and maintenance volunteers and as financial donors. Other project funds have been assembled from the Millennium Commission of the UK 


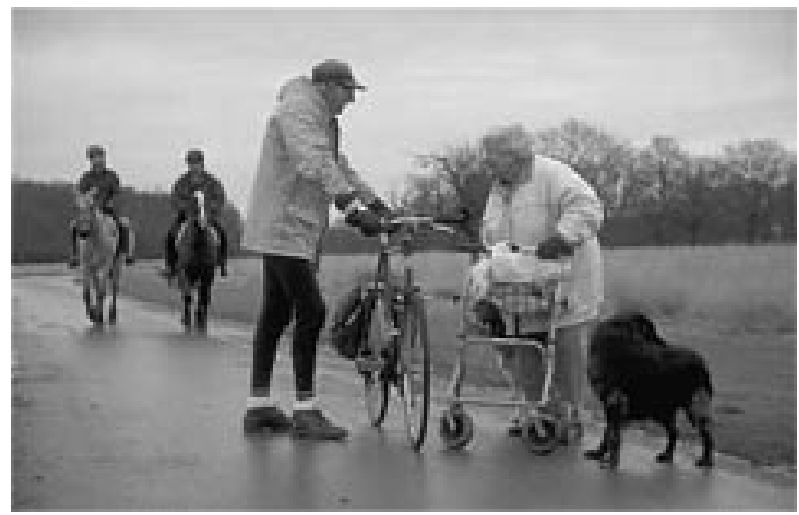

Figure 3 "Regular cycling can keep people of all ages in good shape" by Julia Bayne.

national lottery, national transport funds, local authority funds for transport, recreation and environmental improvement, commercial sponsorship, donations from charitable foundations, works carried out by private developers, European funds, and a range of smaller sources. The total cost to June 2000 was about $£ 210$ million.

The network is made up of more than 1000 individual projects, which range from bridges to new road crossings, signage of existing quiet minor roads to construction of new traffic free paths up to $10 \mathrm{~km}$ in length, and incorporation of cycle access into new developments. Most require planning permission and many include on road sections, which must be implemented by the highway authority. This multi-stage process, over so many individual projects, requires a major coordination effort which is undertaken by Sustrans. One of the most important aspects of the project is to stimulate local authorities to contribute to the Network in all local areas across the country.

By June 2000, the routes of the Network were already highly accessible-11.3 million people in England, Scotland, and Wales (of a total population of about 53 million) lived within $1 \mathrm{~km}$ of a national route (data for Northern Ireland not currently available). It is a key criterion of national route planning that the routes should run through population centres and where possible connect them to schools, shopping areas, and work places. The network therefore has the potential to facilitate short (less than 0.5 mile) commuter journeys by bicycle or on foot that can be incorporated into everyday activity, as well as providing for recreational cycling and walking.

The Network aims to provide safer environments not only for cyclists but also walkers, joggers, wheelchair users, and other non-motorised forms of transport over much of its length (figs 3-5). It has been constructed with an emphasis on aesthetics and has become the UK's largest outdoor art gallery (fig 5). The Network could be potentially an important contributor to improvements in the public health by supporting regular moderate physical activity in pleasant environments.

\section{WHY EVALUATE THE UK NATIONAL CYCLE NETWORK?}

It could be argued that the Network is a "societal public good" with broad aims and as the continuation of this programme is in no way dependent upon demonstrating an effect on population levels of physical activity evaluation is not necessary. We believe, however, that there are several reasons why the effect of the Network on levels of regular physical activity should be evaluated. Firstly, such an evaluation would add to the body of evidence on the effect of environmental change on population levels of physical activity. ${ }^{12}$ Secondly, evaluation may be

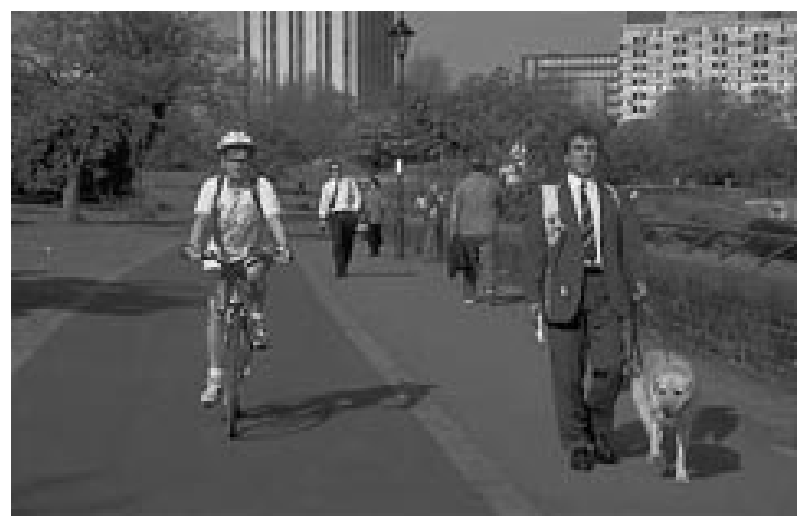

Figure 4 "High quality National Cycle Network routes are useful for most members of the community" by Julia Bayne.

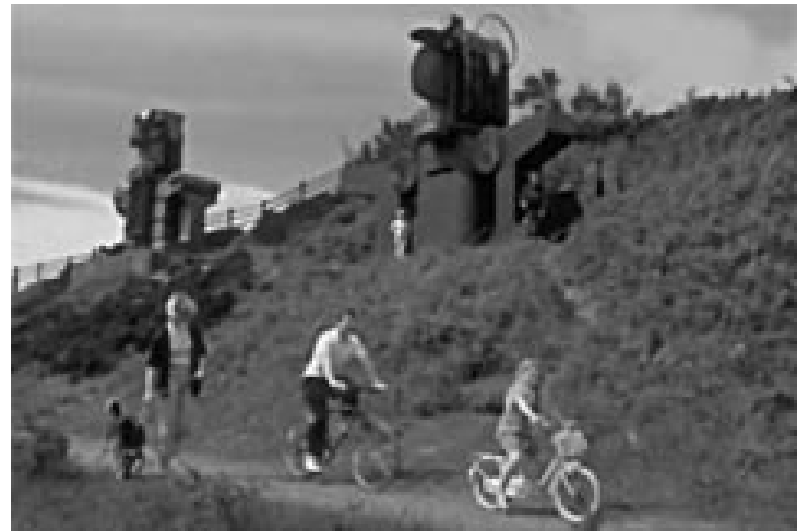

Figure 5 "Art works on the National Cycle Network in County Durham" by Kai.

valuable in shaping the way in which the network develops. For example, process evaluation could seek to identify groups who do not use the Network and reasons for this. Thirdly, the evaluation itself may provide additional impetus for building of further cycle paths in local areas.

\section{DIFFICULTIES OF EVALUATING THE UK NATIONAL CYCLE NETWORK}

Evaluating the effect of the Network on levels of activity is not straightforward. The evaluation must not be too expensive as it makes little sense to set up an elaborate evaluation that is unlikely to provide a definitive answer and costs more than the intervention itself. Although important in evaluating the clinical effectiveness of therapeutic interventions the randomised controlled trial is seldom an appropriate tool for assessing the health impact of an intervention with a population level outcome. ${ }^{21-23}$ More specifically, randomised comparisons might not be meaningful as the differences between comparison areas may take some years to emerge (by which time the control area has been enrolled in the programme). They may also be diluted by building of local cycle paths in the control areas, or they may be dependent on the establishment of an interlinking and extensive network. A way around these problems is to use evidence from a variety of sources to evaluate both the process and outcomes of the Network: "if the resulting data all point in the same direction, it is reasonable to assume that a programme has been successful". ${ }^{23}$ Various sources of information are available or could be collected that could be used together to assess the effect of the Network. These are summarised in table 1 . 


\begin{tabular}{|c|c|c|c|c|}
\hline Approach & Data sources & Potential outcomes & $\begin{array}{l}\text { Developments required to } \\
\text { existing data to improve } \\
\text { value for evaluating cycle } \\
\text { network }\end{array}$ & $\begin{array}{l}\text { Limitations / potential } \\
\text { problems }\end{array}$ \\
\hline User surveys & Local authority user surveys & $\begin{array}{l}\text { Process measures: } \\
\text { Who is using network and for what } \\
\text { purpose } \\
\text { To inform future developments of network } \\
\text { To determine whether users feel network } \\
\text { has increased their likelihood of being } \\
\text { regularly active } \\
\text { To identify groups who do not appear to } \\
\text { use the network }\end{array}$ & $\begin{array}{l}\text { Random selection of survey } \\
\text { sites from across network } \\
\text { Standardisation of data } \\
\text { collection at each site }\end{array}$ & $\begin{array}{l}\text { No information on non-users } \\
\text { (for example, barriers to use } \\
\text { for groups not represented } \\
\text { in user surveys) } \\
\text { Limited use for outcomes } \\
\text { because no comparison } \\
\text { group }\end{array}$ \\
\hline Routine data & $\begin{array}{l}\text { National road traffic survey } \\
\text { National travel survey }\end{array}$ & $\begin{array}{l}\text { Process measures (users and non-users): } \\
\text { Awareness of network } \\
\text { Barriers to use } \\
\text { Outcome measures: } \\
\text { Time-trend analyses }\end{array}$ & $\begin{array}{l}\text { Include details of trips } \\
\text { undertaken on traffic free } \\
\text { routes in surveys } \\
\text { Inclusion of questions } \\
\text { relating to national cycle } \\
\text { network into next round of } \\
\text { survey }\end{array}$ & $\begin{array}{l}\text { May not be possible to } \\
\text { include additional questions } \\
\text { into routine survey } \\
\text { Time-trend analysis- } \\
\text { difficult to be certain the } \\
\text { intervention has definitely } \\
\text { cause any change; latency } \\
\text { period unknown }\end{array}$ \\
\hline $\begin{array}{l}\text { Comparisons } \\
\text { between areas close } \\
\text { to and more distant } \\
\text { from network }\end{array}$ & $\begin{array}{l}\text { Linking routine data from } \\
\text { National Travel Survey and } \\
\text { Health Survey for England to } \\
\text { areas close to and distant } \\
\text { from a cycle pathway }\end{array}$ & $\begin{array}{l}\text { Outcome measures: } \\
\text { Differences between areas in amount of } \\
\text { walking and cycling } \\
\text { Differences between areas in self-reported } \\
\text { levels of physical activity }\end{array}$ & $\begin{array}{l}\text { Linking of routine data to } \\
\text { postcodes and from this to } \\
\text { areas of completed network } \\
\text { paths }\end{array}$ & $\begin{array}{l}\text { May not be possible to } \\
\text { obtain routine survey data } \\
\text { by postcode } \\
\text { Need to be able to } \\
\text { adequately adjust for } \\
\text { potential sociodemographic } \\
\text { confounding factors }\end{array}$ \\
\hline
\end{tabular}

\section{THE ROLE OF UK NATIONAL CYCLE NETWORK USER SURVEYS}

Sustrans has already worked with a number of local authorities to undertake surveys of users of the Network showing that such surveys are feasible. The sites were chosen by local authorities and are therefore not representative of the whole network. Also though the data were collected using the same questionnaire and with standardised protocols: each survey conducted over four 12 hour periods (a weekday during school term and school holidays and a weekend day during school term and school holidays) the data were collected by different interviewers and no attempts were made to monitor or assess differences in approaches between interviewers at each site.

Data from over 7300 network users on 40 routes, were collected in 2000 and 2001. While the results need to be interpreted with caution, because of possible selection and interviewer bias, preliminary analyses of these data provide some useful insights into current use of the network. Fifty one per cent of users were walkers and $46 \%$ cyclists. Forty three per cent indicated that they were using the network for a specific journey, with the remaining $57 \%$ being recreational users. Two thirds of users were male, almost $50 \%$ were aged 45 years or older and $98 \%$ described their ethnicity as white. Some additional questions were added to the questionnaire in 2001. Preliminary analyses of surveys of 22 sites conducted with these additions suggest that pleasant surroundings (24\%), convenience of the route $(22 \%)$, personal fitness $(18 \%)$, and safety of the route $(15 \%)$ were the factors that most influenced use of the network. In addition $42 \%$ stated that the presence of the Network had helped them to increase the amount of regular physical activity that they undertook by a large amount and $28 \%$ by a small amount; only $30 \%$ felt that the Network had made no difference to their activity levels.

There are a number of ways in which these surveys can be improved to provide more useful information. Random selection of survey sites across the entire network and monitoring standardisation of data collection by each set of interviewers would improve the quality of these data. With these improvements it should be possible to assess which factors, for example path type and location, affect the likelihood of the path being used for leisure or regular commuter journeys and whether the existence of the Network is perceived as helping to increase levels of physical activity or not. It should also be possible to determine the extent to which the age, gender, and ethnicity profiles of Network users suggested by the current survey results are determined by survey sites or interviewer bias.

Electronic counters are placed at most survey sites and can be used to validate the manual counts of the interviewers. Extensive use of electronic monitors across the network could be used to monitor changes in use over time. One limitation is that these monitors only detect cycle use and provide no information on pedestrian use or other users of the paths.

The user survey does not include a comparison group so it is impossible to make definite statements regarding the effect of the network on levels of walking and cycling.

\section{THE ROLE OF ROUTINE TRANSPORT DATA}

There are several sources of routine transport data in the UK. These include the UK National Road Traffic Survey and the UK National Travel Survey. The UK National Road Traffic Survey has been used to describe traffic profiles on the public road network since the 1950s. ${ }^{24}$ Data are derived from manual roadside traffic counts and automatic traffic counters at a large number of sites. Figure 1 shows secular trends in mean yearly distances travelled by car and bicycle, over the past 50 years using data from Road Traffic Surveys. From the early 1950s to 1970 there was a steep increase in the distance travelled per year on public roads by car and an equally steep decline in distances travelled per year by bicycle. Since 1970 car use has continued to increase whereas cycling on public roads has exhibited an irregular pattern. Rates of cycling remained stable and at an all time low ( $4 \mathrm{~km}$ per person per year) in the early to mid-1970s. Between the mid-1970s and the mid1990s rates have changed erratically but have tended to be higher (6-7 km per person per year) than in the early 1970s. From the mid-1990s to 1999 cycling rates have returned to the mid-1970s rate of $4 \mathrm{~km}$ per person per year. The changes in cycling over the past 30 years are difficult to explain by any single factor (though the increase in rates in the mid-1970s may have been in response to the oil crisis and petrol price increases). What they tend to suggest, however, is that cycling rates on public roads can change over comparatively short periods of time and may therefore be modifiable. The use of 


\section{Key points}

- Increasing population levels of physical activity will result in improvements in population health.

- Strategies that seek to change the environment to one that is supportive of regular commuting by bicycle or on foot have an important part to play in increasing population activity levels.

- The National Cycle Network is the UK's largest environmental intervention to support such activities.

- Evaluating the effect of the Network on population levels of physical activity would be valuable but is not straightforward.

- We suggest that evaluation should be undertaken combining evidence from network user surveys, routine transport surveys and linking details of development of the network with routine surveys to compare modes of transport and levels of activity between areas close to the network and those more distant from a network path.

data from the National Road Traffic Survey might show increases in cycle use after the completion of the National Cycle Network but is limited because it counts public road traffic only and therefore excludes walkers and users of off road routes. As a large part of the Network is off public roads it may result in increases in both regular cycling and walking that would not be detected by the road traffic surveys.

The National Travel Survey is a household survey of personal travel. ${ }^{25}$ It is the only source of detailed national information in the UK on all types of travel including cycling and walking. The first survey was conducted in 1965 with five further surveys completed between then and 1988. From 1988 the survey has been continuous with fieldwork being carried out every month of the year. Data on sociodemographic factors; travel purpose, mode, length of regular and nonregular journeys; and car, motorbike, and cycle ownership are collected at interview for both the household and individuals within the household. In addition, members of the household are asked to complete a seven day travel diary. In 1999 over 5000 households (representing a 66\% response) were involved in the survey. As with other national surveys, including the 1991 census, young men are underrepresented. ${ }^{26}$ Although some questions and definitions have changed over time it is possible to make corrections for these and the National Travel Survey represents a source of routine data that could be used for examining secular trends in all modes of transport. One limitation of the survey, with respect to the Network, is that it currently excludes journeys that are made on non-trafficked routes. It would be valuable for this exclusion to be removed from future rounds of the survey and for additional questions related to the National Cycle Network to be included. Such data would provide useful process measures, of both Network users and non-users, that complement those from the user surveys.

An important limitation of assessing secular trends in modes of transport from routine travel surveys is that it will be difficult to determine the true contribution of one factor when many are likely to have influenced the observed patterns. In addition, it is difficult to know in advance the probable latency period between completion of the Network and an effect on levels of walking and cycling. If, however, trends based on the National Travel Survey suggested an increase in national cycling and walking levels over the next few years it might be reasonable to assume that the National Cycle Network had contributed to the increase. The contribution of a broader national transport policy aimed at reducing car dependency, however, may make it impossible to determine the exact role of the cycle network.

\section{THE ROLE OF COMPARISONS BETWEEN AREAS CLOSE TO A NETWORK PATH AND THOSE MORE DISTANT}

As the network is still in a process of development and in particular local authority extensions to it will be ongoing for some time it may be possible to link data from routine surveys, via postcodes of respondents and detailed knowledge of the network development, to knowledge of whether respondents were close to or distant from a network route. Data from the UK National Travel Survey ${ }^{25}$ could be used to compare levels of regular cycling and walking between people living in areas close to and more distant from network routes and data from the Health Survey for England ${ }^{27}$ could be used to compare overall levels of physical activity between individuals from each area. It would be necessary to be able to make adequate adjustment for a number of potential confounding factors, such as socioeconomic circumstances and other sociodemographic factors for this approach to be valid. As such data are collected in both the UK National Travel Survey and the Health Survey for England this should be possible. Access to the data by postcodes may not be feasible and may raise issues relating to data protection, ${ }^{28}$ but this approach is worth further investigation. In addition before and after studies of specific projects within the overall Network development programme could be undertaken. For example, a well conducted survey of a community before and after removal of a physical barrier (such as building a bridge across a busy road) between the community and main areas of work and shopping could be undertaken. This would provide information on the effect of a specific activity in a particular context and several such projects may provide information that could be generalised to the whole Network and its future development.

\section{CONCLUSIONS}

Environmental interventions that support regular physical activity are likely to contribute to improving public health. The UK National Cycle Network represents the UK's largest such environmental intervention. Assessing its effect on levels of physical activity is important but is not straightforward. We suggest that rather than set up controlled trials, evaluation could best be undertaken combining evidence from network user surveys, routine transport surveys, and linking details of development of the network with routine surveys to compare modes of transport and levels of activity between areas close to and those more distant from a network path.

\section{Authors' affiliations}

D A Lawlor, A R Ness, Department of Social Medicine, University of Bristol, Bristol, UK

A M Cope, Sustrans North, Newcastle, UK

A Davis, P Insall, Sustrans, Bristol, UK

C Riddoch, Department of Exercise and Health Sciences, University of Bristol

Funding: The National Cycle Network is a Millennium project supported by funds from the National Lottery. The local authority surveys of National Cycle Network users were supported by a grant from the Sainsbury Trust and funds from Sustrans*. DAL is funded by the Medical Research

Council. The views expressed in this publication are those of the authors and not necessarily those of any of the funding bodies.

Competing interests: $A C$ and PI work for Sustrans; $A D$ is a health adviser to Sustrans. All authors walk or cycle regularly.

Correspondence to: Dr D Lawlor, Department of Social Medicine, University of Bristol, Canynge Hall, Whiteladies Road, Bristol BS8 2PR, UK; D.A.lawlor@bristol.ac.uk

Accepted for publication 7 May 2002

\section{REFERENCES}

1 Andersen LB, Schnohr P, Schroll M, et al. All-cause mortality associated with physical activity during leisure time, work, sports, and cycling to work. Arch Intern Med 2000;160:1621-8. 
2 Sesso HD, Paffenbarger RSJ, Lee I-M. Physical activity and coronary heart disease in men. The Harvard Alumni Health Study. Circulation 2000; 102:975-80.

3 Berlin JA, Colditz GA. A meta-analysis of physical activity in the prevention of coronary heart disease. Am J Epidemiol 1990;132:612-28.

4 Morris JN. Exercise in the prevention of coronary heart disease: today's best buy in public health. Med Sci Sports Exerc 1994;26:807-14

5 Physical Activity Task Force. More people, more active, more often. Physical Activity in England. London: Department of Health, 1995.

6 Riddoch CJ, Puig-Ribera A, Cooper A. The effectiveness of physical activity promotion schemes in primary care: a systematic review. London: Health Education Authority, 1998.

7 Lawlor DA, Hanratty B. The effect of physical activity advice given in routine primary care consultations: a systematic review. J Public Health Med 2001;23:219-26.

8 Harland J, White M, Drinkwater C, et al. The Newcastle exercise project: a randomised controlled trial of methods to promote physical activity in primary care. BM 1999;319:828-32.

9 The writing group for the Activety Counseling Trial Research Group. Effects of physical activity counseling in primary care: the Activity Counseling Trial: a randomized controlled trial. JAMA 2001;286:677-87.

10 Bostock L. Pathways of disadvantage? Walking as a mode of transport among low-income mothers. Health and Social Care in the Community 2001;9:11-18.

11 Wardlaw MJ. Three lessons for a better cycling future. BM 2000;321:1582-5

12 Nutbeam D. Creating health-promoting environments: overcoming barriers to action. Aust NZ J Public Health 1997:21:355-9.

13 Hillsdon $M$, Thorogood $M$. A systematic review of physical activity promotion strategies. Br J Sports Med 1996;30:84-9.

14 Department of Environment Transport and the Regions. Transport statistics. Transport trends: walking and cycling in Great Britain. London: A National Statistics publication produced by Transport Statistics: DETR, 2000 .
15 British Medical Association. Road transport and health. London: BMA, 1997.

16 Owen N, Leslie E, Salmon J, et al. Environmental determinants of physical activity and sedentary behavior. Exerc Sport Sci Rev 2000;28: 153-8.

17 Bauman A, Smith B, Stoker L, et al. Geographical influences upon physical activity participation: evidence of a 'coastal effect'. Aust NZ J Public Health 1999;23:322-4

18 Cervero R, Gorham R. Commuting in transit versus automobile neighborhoods. Journal of the American Planning Association 1995:61:210-25

19 Rutten A, Abel T, Kannas L, et al. Self reported physical activity, public health, and perceived environment: results from a comparative European study. J Epidemiol Community Health 2001;55:139-46.

20 Department of Transport. National cycling strategy. London: Department of Transport, 1996.

21 Davey Smith G, Ebrahim S, Frankel S. How policy informs the evidence. BM 2001;322: 184-85

22 Schwartz S, Carpenter KM. The right answer for the wrong question: consequences of type III error for public health research. Am J Public Health 1999;89: 1175-80.

23 Tones K. Beyond the randomized controlled trial: a case for 'judicial review'. Health Educ Res 1997; 12:i-iv.

24 Department of Environment Transport and the Regions. Transport statistics bulletin. Road traffic statistics: 1999. London: A National Statistics publication produced by Transport Statistics: The Stationery Office, 2000

25 Kershaw A. National travel survey technical report. London: Office of National Statistics, 2000

26 Kerrison S, Macfarlane A. Official health statistics: an unofficial guide. London: Arnold, 2000

27 Erens B, Primatesta P. Health survey for England 1998: cardiovascular disease. London: The Stationery Office, 1999

28 Lawlor DA, Stone T. Public health and data protection: an inevitable collision or potential for a meeting of minds? Int J Epidemiol 2001;30:1221-5. 